\title{
Rapid water temperature variations at the northern shelf of the Yellow Sea
}

\author{
Lars Asplin ${ }^{1, *}$, Fan Lin ${ }^{2,3,4}$, W. Paul Budgell ${ }^{1}$, Øivind Strand ${ }^{1}$ \\ ${ }^{1}$ Institute of Marine Research, PB 1870 Nordnes, 5817 Bergen, Norway \\ ${ }^{2}$ Yellow Sea Fisheries Research Institute, CAFS, 106 Nanjing Rd, 266000 Qingdao, PR China \\ ${ }^{3}$ Laboratory for Marine Fisheries Science and Food Production Processes, \\ Qingdao National Laboratory for Marine Science and Technology, 1 Wenhai Rd, Aoshanwei, 266237 Qingdao, PR China \\ ${ }^{4}$ Geophysical Institute, University of Bergen, PB 7803, 5020 Bergen, Norway
}

\begin{abstract}
During summer, there is great spatial variability in bottom water temperature on the northern shelf of the Yellow Sea. This variability is associated with a thermal front along the shelf. Oscillatory currents from semidiurnal and fortnightly period tides transport water masses laterally, resulting in oscillations of bottom water temperature at fixed positions, sometimes with large amplitudes. Temperature variations, as demonstrated in the present work, can cause damage to bottom-cultured scallops. In particular, in the scallop sea ranching area near Zhangzidao Island, such oscillations are evident in late summer. We constructed a spatial index of aggregated temperature variability from current model results identifying how temporal variability during the summer period varies in space. This information can be useful both in selecting favorable ranching areas and designing laboratory stress experiments on aquaculture candidate species.
\end{abstract}

KEY WORDS: Northern Yellow Sea shelf · Sea ranching $\cdot$ Current modelling $\cdot$ Yellow Sea Model Tidal front

\section{INTRODUCTION}

The northern shelf of the Yellow Sea is a shallow shelf area extending approximately $200 \mathrm{~km}$ in the along-shore direction and $20-50 \mathrm{~km}$ in the crossshore direction, with a mean depth of approximately $40 \mathrm{~m}$. The currents are dominated by the tidal flow, with smaller contributions from wind-driven flow and a seasonal thermal jet (Lin et al. 2019). The water masses are seasonally heated and cooled, creating a large amplitude between the warmest water in summer and coldest in winter, with a typical range of bottom water temperature from $<5$ to $>20^{\circ} \mathrm{C}$. Due to mixing energy input from the tide combined with the shallow sloping bathymetry, a thermal front in the along-shore direction is established during the spring and summer (Simpson \& Hunter 1974, Hill et al. 2008), and the water temperature difference

*Corresponding author: lars.asplin@imr.no across this front can be several degrees (Lin et al. 2019).

The northern shelf area is important for aquaculture, where sea ranching of the Japanese scallop Patinopecten yessoensis has been of particular economic importance (Zhou 2012). Ranching is carried out by releasing juveniles to bottom habitats, where the scallops usually reach market size after 3 yr. Mortalities of scallops in sea ranching within this region have been related to large bottom-water temperature variations in summer (Zhao et al. 2019). The water masses on the shelf oscillate back and forth over many $\mathrm{km}$, mainly due to the various components of the tidal forcing (Lin et al. 2019). In areas with large horizontal bottom temperature gradients, e.g. in the region of the seasonal thermal front, periodically large variations of water temperature will occur and potentially expose individual scallops to water

(C) The authors 2021. Open Access under Creative Commons by Attribution Licence. Use, distribution and reproduction are unrestricted. Authors and original publication must be credited. 
temperature amplitudes of several degrees at tidal and longer frequencies (Lin et al. 2019). Previous records of massive mortality of cultured scallops have mostly been related to temperature extremes, reproduction processes, overcrowding and invaders or pathogens (Strand \& Brynjeldsen 2003, Xiao et al. 2005, Shumway \& Parsons 2016). Knowledge is lacking on how temperature variations at short temporal scales impact bivalves. However, recent experimental studies have shown that physiology, metabolism and immune functions in $P$. yessoensis are affected by acute temperature changes assumed to represent the temperature gradients on the northern shelf (Jiang et al. 2016, 2018a,b, Gao et al. 2017). Such temperature stress may act as a major factor in causing the observed mortality of scallops, but more information on spatial and temporal temperature variability is needed to understand its role in explaining the mortality.

The objective of our study was to demonstrate that high-resolution temporal and spatial bottom temperature variability based on numerical current model results for the Yellow Sea can be used to support risk assessment and sustainable management of scallop sea ranching on the northern shelf areas. The numerical model results we used have previously been validated for the northern shelf of the Yellow Sea and were found to be reasonably accurate (Lin et al. 2019). We identified the semidiurnal tidal current and a fortnightly oscillating current as being responsible for the variable bottom temperatures. From the time series of oscillating bottom temperatures, we created a spatially varying index representing the aggregated temporal temperature variation at the shelf area of relevance for scallop sea ranching. This index can be used to identify site and area suitability for sea ranching of scallops as well as help to explain differences in scallop mortality between years.

\section{MATERIALS AND METHODS}

\subsection{The current model}

We used the Regional Ocean Modeling System (ROMS) for our study (Shchepetkin \& McWilliams 2005, Haidvogel et al. 2008). ROMS is solving the primitive hydrostatic equations including a free surface. The numerical grid has terrain following vertical coordinates and a rectangular Arakawa-C grid horizontally. Internationally, ROMS has been widely used in coastal studies, including along the Norwegian coast (Albretsen et al. 2012, Asplin et al. 2020). Our implementation of the ROMS for the Yellow Sea is a transfer of the model implementation along the Norwegian coast; it is named the Yellow Sea Model (YSM) and covers the Bohai Sea and the Yellow Sea. The horizontal grid size of the model is $1 \mathrm{~km}$ and there are 40 vertical terrain following layers. The resolution near the surface and the bottom is in $\mathrm{dm}$ and at the bottom is in $\mathrm{m}$. The actual spacing is dependent on water depth. The model grid is rotated and has an open boundary towards the border between the Yellow Sea and the East China Sea. Bottom topography is interpolated from SRTM30-plus shuttle radar altimetry and the GEBCO 30' database (Becker et al. 2009) (Fig. 1). Horizontally, the model uses a $3^{\text {rd }}$ order upstream horizontal advection scheme for tracers and a $4^{\text {th }}$ order centered advection scheme for momentum. Vertically, the model uses the Generic Length Scale k-kl vertical mixing scheme (Warner et al. 2005).

The atmospheric forcing component of the model is from the European Centre for Medium-Range Weather Forecast ERA-Interim Reanalysis data sets (Dee et al. 2011). The forcing contains wind velocity

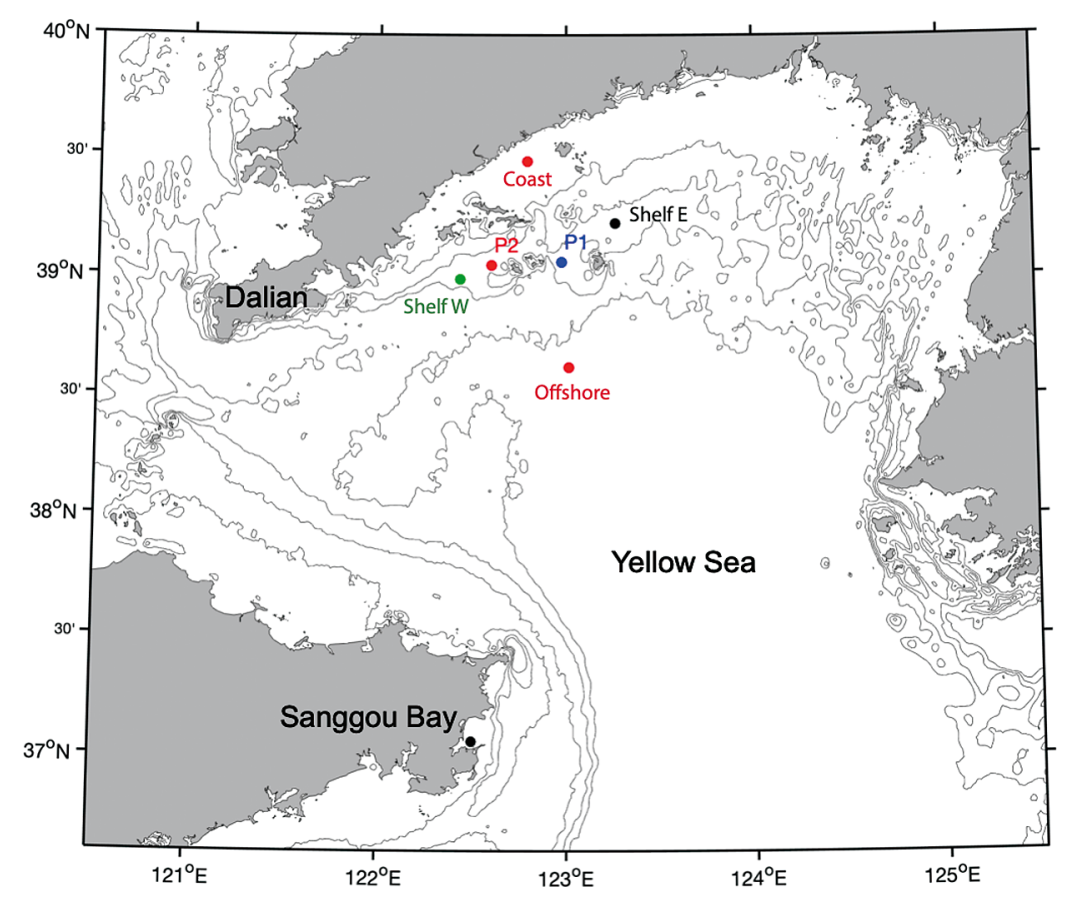

Fig. 1. The northern part of the Yellow Sea. Lines represent bathymetry every $10 \mathrm{~m}$ between 20 and $50 \mathrm{~m}$ depths. Colored dots: time series locations; P1: location of the current observations; P2: location of more detailed analysis of the bottom temperature variations. Zhangzidao Island is between P1 and P2 
at $10 \mathrm{~m}$ height, surface-specific humidity derived from $2 \mathrm{~m}$ dew point temperature, surface air temperature at $2 \mathrm{~m}$, downward longwave and shortwave radiation, precipitation and mean sea level pressure. Accumulated data such as radiation and precipitation are specified at $12 \mathrm{~h}$ intervals while the rest are at $6 \mathrm{~h}$ intervals. The atmospheric forcing was originally on a $3 \mathrm{~km}$ grid and is interpolated in the model grid. Net heat flux is computed from bulk formulae by Fairall et al. (1996).

At the open boundary, information of the tide, the daily mean sea surface elevation and daily values of currents, temperature and salinity in the vertical are specified. The values are taken from the HYCOM daily global ocean reanalysis (www.hycom.org). Eleven tidal components (M2, K2, S2, N2, K1, P1, O1, Q1, MN4, M4 and MS4 constituents) were taken from the Oregon State University global inverse tidal model TPXO7.2 (Egbert \& Erofeeva 2002) and were specified at the open boundary. Open boundary data enter the domain using a radiative-nudging scheme. A quadratic bottom drag with a friction coefficient of 0.0025 is applied to the entire model domain.

The model results are based on a simulation with realistic forcing from August 2013 to December 2015. The initial conditions were interpolated from the HYCOM reanalysis. We store the model results as hourly and daily mean values. The model was also run for 2017 with only the tidal forcing activated, isolating this current component. The reason for selecting this period is an overlap with available current observations.

\subsection{The observations}

Current observation data are from moored acoustic Doppler current profilers (ADCPs) from 2 periods. From September to December 2015, current was measured by a Nortek ADCP 1 $\mathrm{MHz}$ Aquadopp Profiler (www.nortek group.com) with $1 \mathrm{~m}$ bin size and 20 bins, located near Zhangzidao Island at Site P1 (Fig. 1), measuring upwards. The accuracy of the instrument was $1 \%$ measured value $\pm 0.5 \mathrm{~cm} \mathrm{~s}^{-1}$ for current profiling, $\pm 0.1^{\circ} \mathrm{C}$ for the integrated temperature sensor and $0.5 \%$ of maximum range for the pressure sensor. In July and August 2017, an RDI ADCP $300 \mathrm{KHz}$ profiler (http://www. teledynemarine.com/adcps/marine- measurements/) was moored at another location near Site P1. The accuracy of the current for the RDI instrument was $0.5 \%$ of the measured value $\pm 0.5 \mathrm{~mm} \mathrm{~s}^{-1}$. The ADCP measured the whole water column with a vertical bin resolution of $2 \mathrm{~m}$.

\section{RESULTS}

The typical seasonal cycle of temperature for the water masses on the northern shelf of the Yellow Sea has a large amplitude, with maximum water temperature occurring in September and minimum in March. At Site P2 (Fig. 1), the time series of modelled surface and bottom temperature for 2014 and 2015 illustrate that the water masses are homogenized during late fall and winter and stratified during summer (Fig. 2). The depth at this location is $32 \mathrm{~m}$. In areas on the shelf with depths shallower than 15-20 m, the water will be mostly homogeneous all year due to vertical mixing from the strong tide.

The spatial temperature difference is also high in late summer with a strong offshore gradient of the bottom temperature (Fig. 3). The temperature difference from the deeper outer part of the shelf to the shallower inner part is typically $\sim 10^{\circ} \mathrm{C}$ in mid-September. The areas along the thermal front will be vulnerable to temperature variations if the water masses oscillate in the cross-front direction.

To illustrate the temporal variability at various locations at the shelf, we extracted time series of bottom water temperatures from 4 locations in the region of the thermal front (Shelf W, P1, P2 and Shelf $E_{i}$ Fig. 1), one from a location near the coast, one in

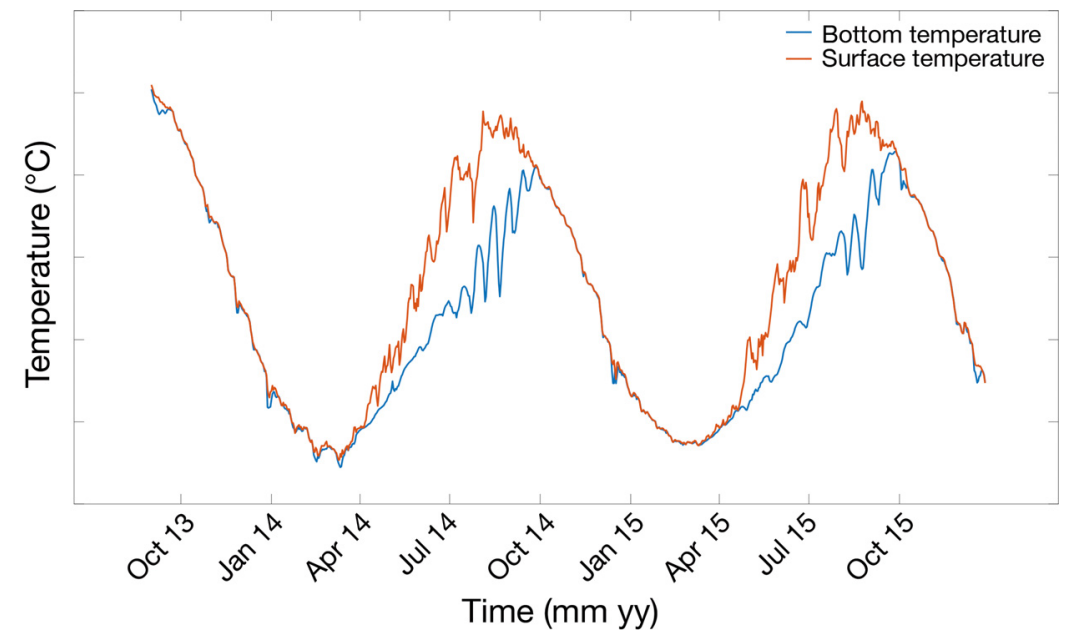

Fig. 2. Time series of water temperature at the surface (red line) and the bottom (blue line) from Site P2, west of Zhangzidao Island 


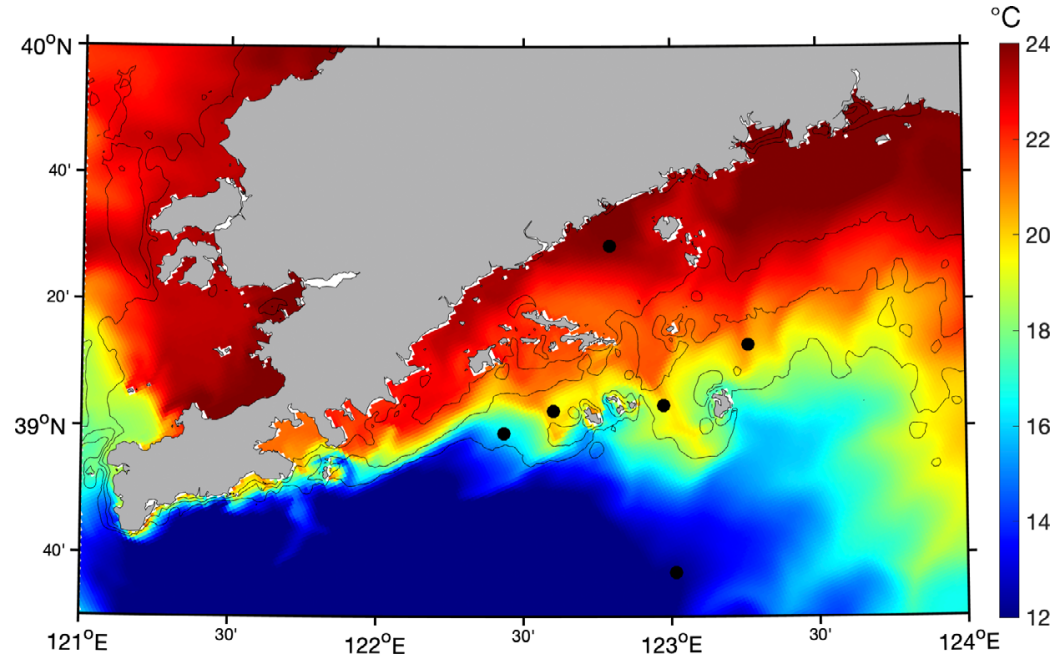

Fig. 3. Bottom water temperature on 15 September 2014, from the numerical current model results. Black lines: isobaths for 20, 30 and 40 m depths; black dots: locations where time series were extracted (see Fig. 1) the water temperature reaches its maximum value. The amplitude of these oscillations is several degrees Celsius and a period of approximately $2 \mathrm{wk}$ is apparent. At the 2 easternmost locations (Shelf E and P1; black and blue lines in Fig. 4) such oscillations are less pronounced. The strongest seasonal signal occurs at the location close to the coast (red dotted line in Fig. 4), whereas the seasonal signal is much reduced offshore (blue dotted line in Fig. 4). On the other side of the sea in the other large aquaculture area at Sanggou Bay, the temperature variation is also relatively strong (black dotted line in Fig. 4).

A closer view of the bottom temperature at Site P2 (Fig. 1) illustrates the oscillations with temperature amplitudes of several degrees (Fig. 5). Both the full temporal resolution with hourly values from the numerical model results and the $48 \mathrm{~h}$ low-pass filtered values are presented. The difference between these 2 time series is shown as a black line in Fig. 5, illustrating the variability due to the strong high frequency tidal flow only. Superposed on the high frequency oscillations of the semidiurnal tide $\left(\mathrm{M}_{2}, \sim 12.4 \mathrm{~h}\right)$ we have 4-5 low-frequency oscillations of $\sim 2 \mathrm{wk}$ period and amplitudes up to more than $2{ }^{\circ} \mathrm{C}$ in the late summer in both 2014 and 2015. the open sea and one across the sea in the Sanggou Bay, which is another intensive aquaculture area. After reducing the diurnal and semidiurnal tidal signals with a $48 \mathrm{~h}, 4^{\text {th }}$ order Butterworth filter, we see the strong seasonal signal with bottom water temperatures higher than $20^{\circ} \mathrm{C}$ in late summer and lower than $5^{\circ} \mathrm{C}$ in the winter (Fig. 4). The 4 locations on the northern shelf vary similarly throughout the season, but the 2 westernmost locations (P2 and Shelf W; red and green colored lines in Fig. 4) experience some large oscillations in August and September before
Bottom water temperature

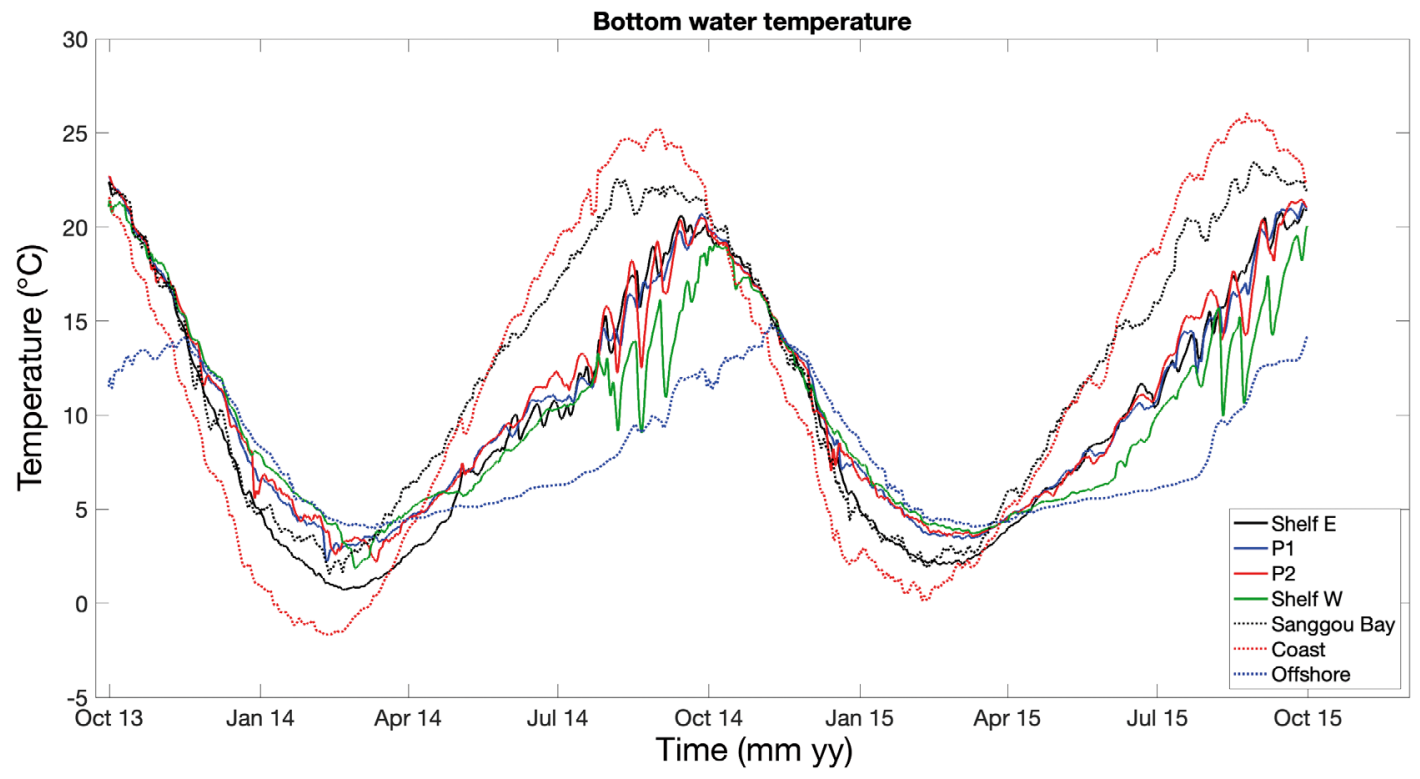

Fig. 4. Time series of bottom water temperature from locations at the northern shelf of the Yellow Sea and at Sanggou Bay. The positions are marked on the map in Fig. 1, and the line colors are similar to the colors of the dots. Black dotted line: Sanggou Bay location; red dotted line: location near the coast; blue dotted line: location offshore in the ocean 


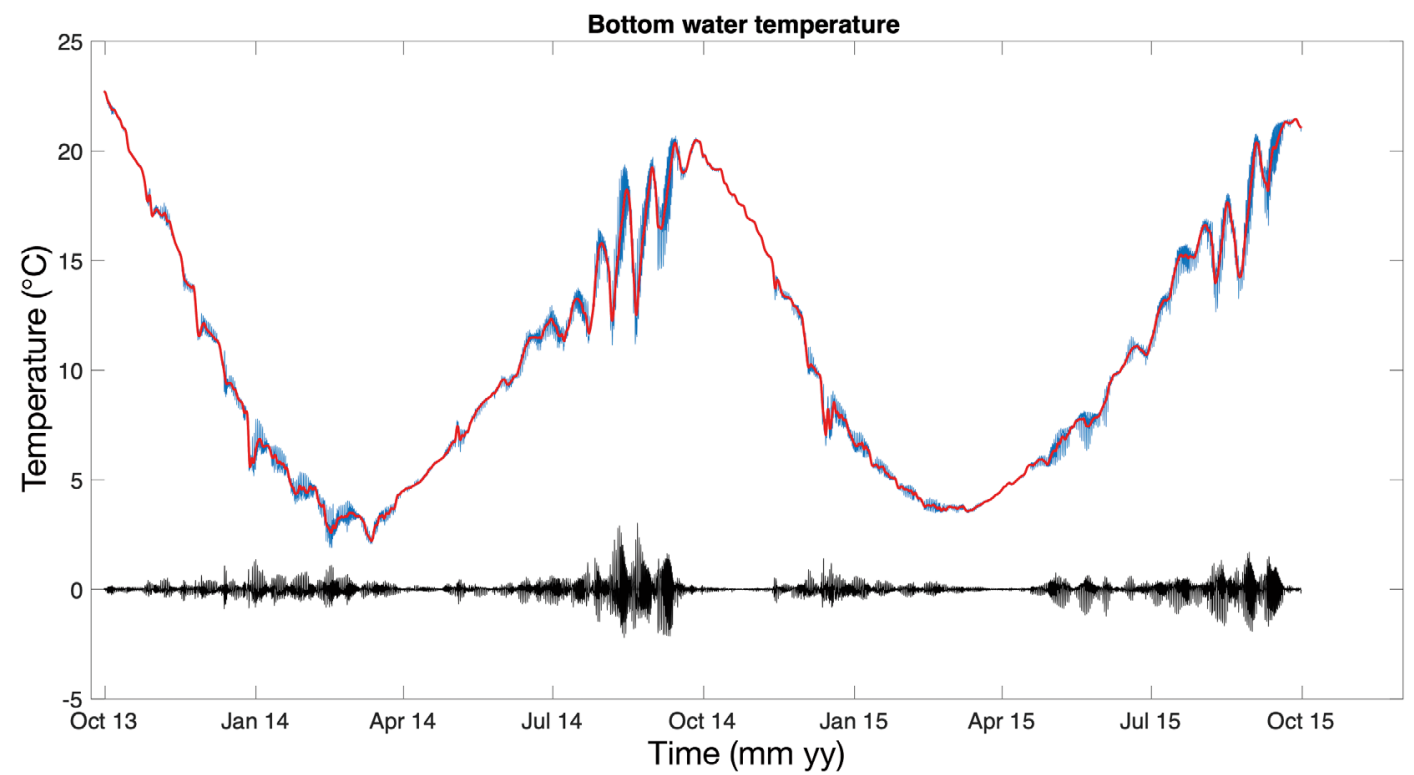

Fig. 5. Time series of bottom temperature (blue line), the low-passed values (red line) and the difference between the 2 (black line) at Site P2, west of Zhangzidao Island

The temperature oscillations with the longer period must be due to a slowly oscillating current component superposed on the higher frequency tidal flow. From a $7 \mathrm{~d}$ low-pass filtered time series of the bottom current component along the North-South direction, we indeed find small amplitude oscillations $(1-2 \mathrm{~cm}$ $\mathrm{s}^{-1}$ ) with a typical period of $\sim 2 \mathrm{wk}$ (Fig. 6). The time series are from the 2 locations on the shelf (Sites P1 and P2 in Fig. 1) as well as the observed bottom current near Site P1. The currents are from a depth above the frictional bottom layer. The time period covers 2014 and 2015 for the model results and late fall 2015 for the observations. The modelled current has a net southerly component and there is a seasonal signal with a stronger southerly flow during summer.

In order to further investigate the nature of these long period current oscillations, the YSM was run for 2017 with only tides as forcing, i.e. other forcing mechanisms such as wind, radiation, runoff and a daily open boundary forcing were omitted. The current components along the $x$ - and $y$-directions of the model grid after $7 \mathrm{~d}$ low-pass filtering reveal current oscillations with a near $14 \mathrm{~d}$ period and a magnitude

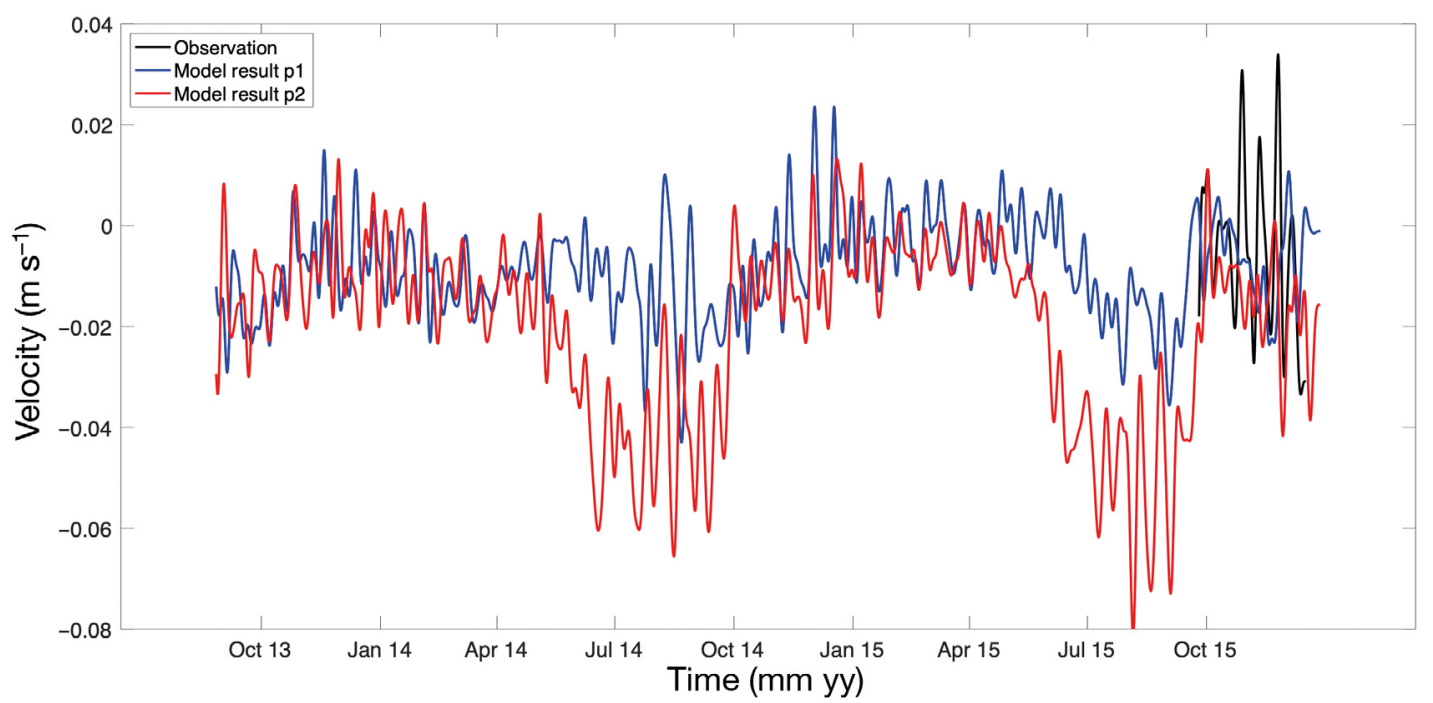

Fig. 6. Time series from the model results of $7 \mathrm{~d}$ low-passed north-south current component close to the bottom at Sites P1 and P2. The black line is a similar current component from the observations near P1 


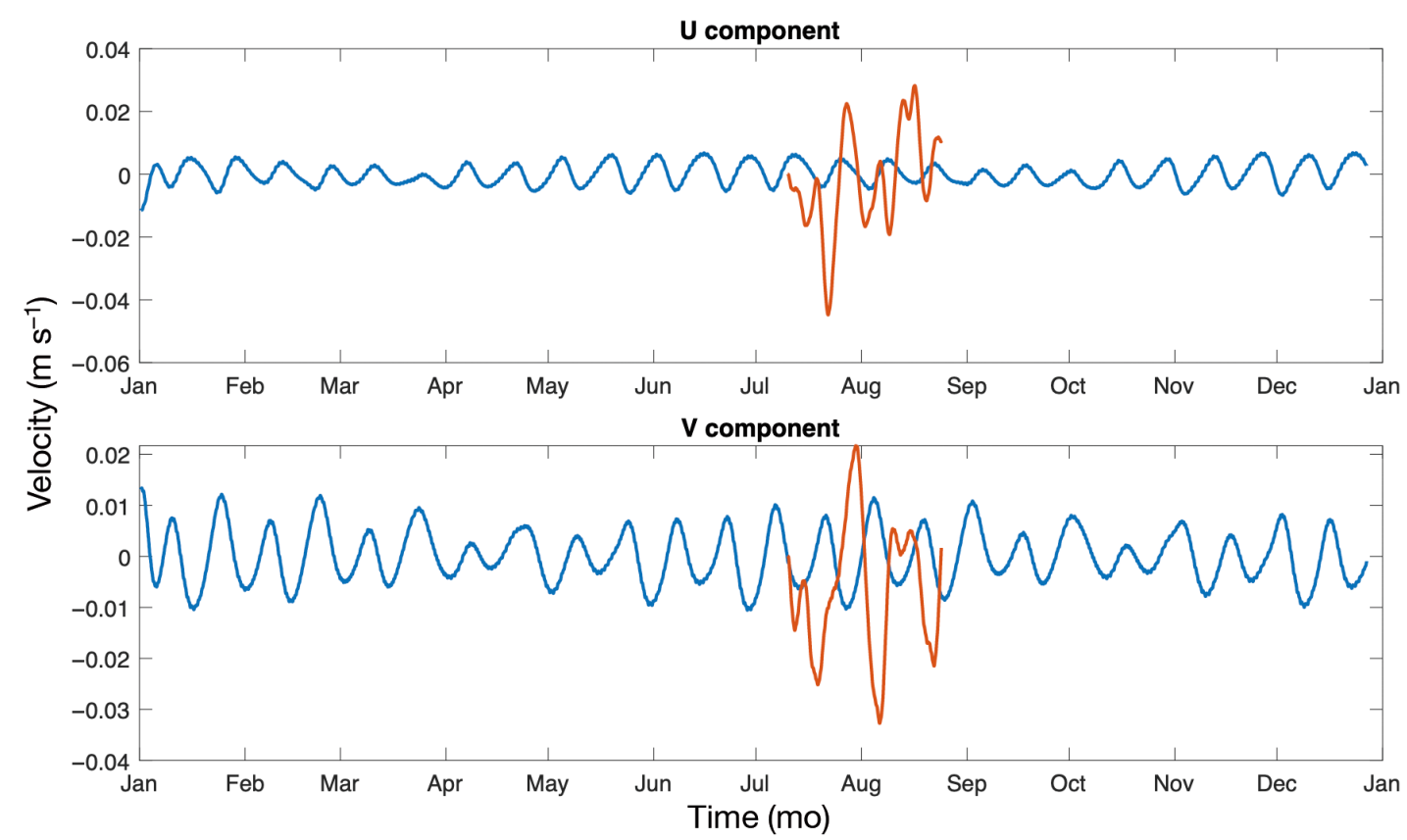

Fig. 7. Time series of $7 \mathrm{~d}$ low-passed current component close to the bottom at Site P1 from the model results of the tides only simulation of 2017. Red line: similar current component from observations, including additional forcing compared to the model results

around 1-2 $\mathrm{cm} \mathrm{s}^{-1}$ (Fig. 7). Observations from this location (red line) also reveal similar oscillations and amplitude, although they are not directly comparable since the numerical model results lack all the available forcing.

Based on the numerical model results, we can spatially quantify the influence of both the low-frequency bottom temperature oscillations and the (mostly) semidiurnal tidal oscillations in late summer. From individual oscillations, we multiply the temperature difference between the maximum and minimum temperatures in the first half of the wavelength with the time between the 2 in days and sum these values at each grid square in the numerical model domain. We call this index 'dt*days' (with units $\left[{ }^{\circ} \mathrm{C}\right.$ day]), and it will represent an aggregated value of the temperature oscillation effect at that location. Hence, this can be viewed as a measure of an environmental stress on the organisms. The period 1 July to 30 September is when the thermal front along the shelf is well established. The geographical distribution of the 'dt*days' index shows that the highest values mainly appear at locations with bathymetry between 20 and $40 \mathrm{~m}$, where the thermal front is located (Fig. 8a-d). We split the index values between those generated by oscillations from the semidiurnal tide (Fig. 8c,d) and those generated by longer period oscillations (Fig. 8a,b). Obviously, the semidiurnal tides generate higher values of the index com- pared to those of the longer period oscillations. We also find differences between years in the 'dt*days' index, mostly attributable to the influence of the long-period oscillations.

Spatially aggregated values of the ' $\mathrm{dt}^{*}$ days' index as an average for the 2 summer periods for the whole domain shown in Fig. 8 reveal relatively similar values (Table 1). The index is nearly twice as high from the semidiurnal oscillations compared to the longer period oscillations. The mean values for the whole shelf area do not differ appreciably between the summers of 2014 and 2015. This is not the case, however, if we perform this calculation only for the scallop ranching area marked by the black rectangle in Fig. 8a. For this area, which is located close to the thermal front, we find larger variability between years and especially in the values from the longperiod oscillations.

\section{DISCUSSION}

We have shown that the bottom water temperature can oscillate by several degrees in amplitude and last many weeks in areas along the northern shelf of the Yellow Sea. This occurs mostly in late summer when the thermal front is established. The period of oscillations is either semidiurnal or approximately $14 \mathrm{~d}$. The reason for these temperature fluctuations at specific 

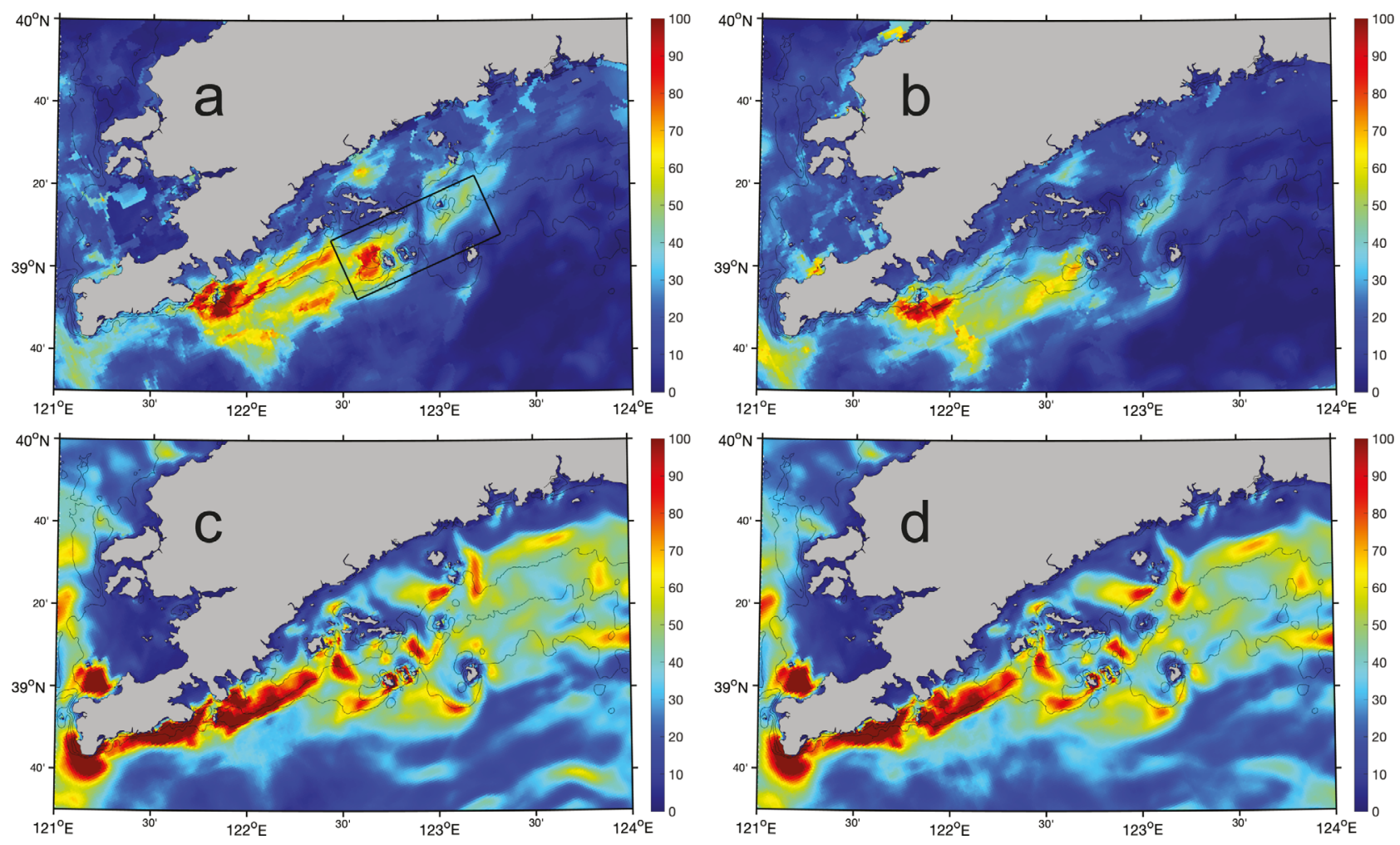

Fig. 8. Geographical distribution of the 'dt*'days' index for the period 1 July to 30 September in (a,c) 2014 or (b,d) 2015, based on $(a, b)$ low-passed bottom temperature time series or $(c, d)$ original bottom temperature time series. Lines: isobaths for 20,30 and $40 \mathrm{~m}$ depth; black rectangle: production area for Japanese scallops

Table 1. Spatial mean values of the 'dt*days' index for the whole northern shelf area and scallop ranching area (in parenthesis) based on the bottom temperature low-passed time series (long period) and the pure tidal component (semidiurnal)

\begin{tabular}{|lccc|}
\hline Time & $\begin{array}{c}\text { De-tided } \\
\left({ }^{\circ} \mathrm{C} \text { day }\right)\end{array}$ & $\begin{array}{c}\text { Hourly tidal } \\
\left({ }^{\circ} \mathrm{C} \text { day }\right)\end{array}$ & $\begin{array}{c}\text { Sum } \\
\left({ }^{\circ} \mathrm{C} \text { day }\right)\end{array}$ \\
\hline Summer 2014 & $14(35)$ & $24(49)$ & $38(84)$ \\
Summer 2015 & $15(24)$ & $25(45)$ & $40(69)$ \\
\hline
\end{tabular}

locations is the combination of an oscillatory current and a spatial temperature gradient. Thus, both the semidiurnal tidal flow (i.e. the $\mathrm{M}_{2}$ component) and the low frequency and much weaker fortnightly oscillating flow will move water of different temperature back and forth.

It is well known that on shallow shelves with a strong tidal flow, a thermal front can be established with vertical homogeneous water in the onshore direction or towards shallower depths and a thermal stratification offshore or towards deeper water (Simpson \& Hunter 1974, Hill et al. 2008). This is also the case on the northern shelf during the summer with an along-shore thermal front mainly following the 20-30 m isobaths (Lin et al. 2019). The sea ranching areas near Zhangzidao Island were situated in the middle of the frontal zone in September 2014.

The movement of the water from the semidiurnal tide will typically be $5-10 \mathrm{~km}$ back and forth (Lin et al. 2019). Longer oscillations will move the water back and forth $5-10 \mathrm{~km}$ given that the water speed is $0.01-0.02 \mathrm{~m} \mathrm{~s}^{-1}$ and the period of the oscillation is around $14 \mathrm{~d}$. Thus, the total area affected can have a radius of $10-20 \mathrm{~km}$ depending upon the phases of the 2 oscillations.

The low frequency oscillation appears in both the numerical model results and the observations. Even though the current speed is low, its duration of flow in the same direction makes it important. After running the numerical model forced by tides only, the oscillations appear year-round and are a permanent phenomenon (Fig. 7). In the results of the simulation including all forcing mechanisms, we find an even longer seasonal signal (Fig. 6). This might be of importance. The origin could be variations in stratification or the seasonality of the winds; however, this is beyond the scope of the present investigation. 
The $14 \mathrm{~d}$ signal in the current field could be produced by nonlinear advection processes that generate compound shallow water tidal constituents at the sum (quarter-diurnal MS4) and difference (fortnightly MSF) of the lunar M2 and S2 tidal frequencies (Godin 1972). The spring-neap modulation of the semi-diurnal tide can produce fortnightly variations in the strength of vertical mixing (Haas 1977, Budgell 1982) which can lead to fortnightly variations in bottom temperature. The circulation is also affected in an indirect manner on a $14 \mathrm{~d}$ time scale by spring-neap variations in frontal structure caused by changes in vertical mixing (Li \& Zhong 2009).

We found differences between the summers of 2014 and 2015 in the 'dt*days' index, but mostly these appear in space. When considering the whole northern shelf, the difference between 2014 and 2015 is small (Table 1). However, inside the scallop production area (Fig. 8a) the index is more than $20 \%$ higher in 2014 compared to 2015. This difference is mostly due to the contribution from the long period oscillations. This can be interpreted as the location of the seasonal thermal front varying between years. The mechanisms behind the front are the tidal current, bottom topography, atmospheric radiation (heat exchange) and other mixing agents like wind. Only the last 2 will change between years; thus, the atmospheric conditions will probably cause the interannual differences of the thermal front strength and location. The difference of the ' $\mathrm{dt}^{*}$ days' index between 2014 and 2015 illustrates that there can be a temporal-spatial shift in the bottom temperature patterns and magnitude. Experimental studies by Jiang et al. $(2016,2018 a, b)$ indicate that acute temperature variations are more critical to the scallops than variations at longer periods. This factor will be affected by such temporal-spatial shifts and influences how the risk of scallop mortality should be assessed.

The spatial-temporal variability of the temperature gradients shown in our study is crucial information for designing experiments to better understand stress responses of Patinopecten yessoensis and ultimately the role of the temperature environment in explaining their growth and mortality in sea ranching (Zhao et al. 2019). In previous studies, indices typically representing the temperature environment integrated over time (e.g. growing degree days) have been used in assessing temperature-dependent growth and development in several molluscan species (Broell et al. 2017, Steeves et al. 2018). To our knowledge, none of the previous studies used indices involving representation of the degree of temperature oscillations. The variability in the ' $\mathrm{dt}^{*}$ days' index is an approach normalizing the temperature environment assumed to detrimentally affect the scallops over the spatial domain in the sea ranching area. However, better understanding of physiological and immunological factors affecting the mortality of the scallops is needed to access thresholds for mortality in sea ranching conditions (Jiang et al. 2018a,b). Therefore, more research needs to be completed before higher accuracy can be provided in developing temperature indices for risk assessment and site or area selection for the scallop releases. Such indices would clearly contribute to the development of sustainable sea ranching and would likely provide direct economic benefit to the aquaculture industries in the area.

The results from the YSM reproduced the ambient environment reasonably well. These results will be available for further investigations. We believe that this information, in combination with specifications of the relationship between physical stress on the cultured scallops and the effects on scallop growth and survival, can be used to identify favorable sea ranching conditions. Temperature variations extracted from model results can provide crucial information for further physiological study of high frequency stress.

Acknowledgements. The authors sincerely appreciate the support from Sea Ranching Research Center of Zoneco, for their help in making observations. The authors also thank the European Center for Medium-Range Weather Forecasts for the atmospheric data, the international team of GEBCO for bathymetry data and NOPP for HYCOM data. This research was supported by the Research Council of Norway (249056/H30), Environment and Aquaculture Governance (MFA, CHN 17/0033) and Horizon 2020 IMPAQT project (774109). This research was also supported by the Key Programme for International Cooperation on Scientific and Technological Innovation, Ministry of Science and Technology (2017YFE0118300).

\section{LITERATURE CITED}

Albretsen J, Aure J, Sætre R, Danielssen DS (2012) Climatic variability in the Skagerrak and coastal waters of Norway. ICES J Mar Sci 69:758-763

Asplin L, Albretsen J, Johnsen IA, Sandvik AD (2020) The hydrodynamic foundation for salmon lice dispersion along the Norwegian coast. Ocean Dyn 70:1151-1167

Becker JJ, Sandwell DT, Smith WHF, Braud J and others (2009) Global bathymetry and elevation data at 30 arc seconds resolution: SRTM30_PLUS. Mar Geod 32: 355-371

*Boell F, McCain JSP, Taggart CT (2017) Thermal time explains size-at-age variation in molluscs. Mar Ecol Prog Ser 573:157-165

Budgell WP (1982) The influence of the spring-neap tidal cycle upon vertical stratification in Chesterfield Inlet, Hudson Bay. Nat Can 109:709-718 
Dee DP, Uppala SM, Simmons AJ, Berrisford P and others (2011) The ERA-Interim Reanalysis: configuration and performance of the data assimilation system. Q J R Meteorol Soc 137:553-597

Egbert GD, Erofeeva SY (2002) Efficient inverse modeling of barotropic ocean tides. J Atmos Ocean Technol 19:183-204

Fairall CW, Bradley EF, Rogers DP, Edson JB, Young GS (1996) Bulk parameterization of air-sea fluxes for tropical ocean-global atmosphere coupled-ocean atmosphere response experiment. J Geophys Res Oceans 101:3747-3764

Gao G, Zhang J, Li M, Ma S, Guo X, Jiang W, Lv X (2017) Effects of temperature fluctuation on physiological and immune parameters of scallop (Patinopecten yessoensis). Yuye Kexue Jinzhan 38:148-154 (In Chinese)

Godin G (1972) The analysis of tides. University of Toronto Press, Toronto

Haas LW (1977) The effect of the spring-neap tidal cycle on the vertical salinity structure of the James, York and Rappahannock Rivers, Virginia, USA Estuar Coast Mar Sci 5:485-496

Haidvogel DB, Arango H, Budgell WP, Cornuelle BD and others (2008) Ocean forecasting in terrain-following coordinates: formulation and skill assessment of the Regional Ocean Modeling System. J Comput Phys 227:3595-3624

Hill AE, Brown J, Fernand L, Holt J and others (2008) Thermohaline circulation of shallow tidal seas. Geophys Res Lett 35:L11605

Jiang W, Li JQ, Gao YP, Mao YZ and others (2016) Effects of temperature change on physiological and biochemical responses of Yesso scallop, Patinopecten yessoensis. Aquaculture 451:463-472

Jiang W, Lin F, Fang J, Gao Y and others (2018a) Transcriptome analysis of the Yesso scallop, Patinopecten yessoensis gills in response to water temperature fluctuations. Fish Shellfish Immunol 80:133-140

Jiang W, Du M, Fang J, Gao Y and others (2018b) Response of Yesso scallop Patinopecten yessoensis to acute temperature challenge: physiological and biochemical parame-

Editorial responsibility: Jonathan Grant,

Halifax, Nova Scotia, Canada

Reviewed by: 3 anonymous referees ters. J Oceanol Limnol 37:321-329

Ki M, Zhong L (2009) Flood-ebb and spring-neap variations of mixing, stratification and circulation in Chesapeake Bay. Cont Shelf Res 29:4-14

Lin F, Asplin L, Budgell WP, Wei H, Fang J (2019) Currents on the northern shelf of the Yellow Sea. Reg Stud Mar Sci 32:100821

Shchepetkin AF, McWilliams JC (2005) The regional oceanic modeling system (ROMS): a split-explicit, freesurface, topography-following-coordinate oceanic model. Ocean Model 9:347-404

Shumway SE, Parsons GJ (eds) (2016) Scallops: biology, ecology, aquaculture and fisheries, $3^{\text {rd }}$ edn. Elsevier Science, Oxford

Simpson JH, Hunter JR (1974) Fronts in the Irish Sea. Nature 250:404-406

* Steeves LE, Filgueira R, Guyondet T, Chassé J, Comeau L (2018) Past, present, and future: performance of two bivalve species under changing environmental conditions. Front Mar Sci 5:184

Strand Ø, Brynjeldsen E (2003) On the relationship between low winter temperatures and mortality of juvenile scallops, Pecten maximus L., cultured in western Norway. Aquacult Res 34:1417-1422

*Warner JC, Sherwood CR, Arango HG, Signell RP (2005) Performance of four turbulence closure models implemented using a generic length scale method. Ocean Model 8:81-113

Xiao J, Ford S, Yang H, Zhang G, Zhang F, Guo X (2005) Studies on mass summer mortality of cultured zhikong scallops (Chlamys farreri Jones et Preston) in China. Aquaculture 250:602-615

Zhao Y, Zhang J, Lin F, Ren JS and others (2019) An ecosystem model for estimating shellfish production carrying capacity in bottom culture systems. Ecol Modell 393:1-11

Zhou JH (2012) Preliminary study on structure and characteristic of Yesso scallop industry in LiaoNing. MSc dissertation, The Ocean University of China, Qingdao (in Chinese)

Submitted: June 12, 2020

Accepted: January 18, 2021

Proofs received from author(s): April 22, 2021 